\title{
INTROSPECTIVE ACQUAINTANCE: AN INTEGRATION ACCOUNT
}

\author{
Anna Giustina
}

\begin{abstract}
In this paper, I develop a new version of the acquaintance view of the nature of introspection of phenomenal states. On the acquaintance view, when one introspects a current phenomenal state of one's, one bears to it the relation of introspective acquaintance. Extant versions of the acquaintance view neglect what I call the phenomenal modification problem. The problem, articulated by Franz Brentano in his Psychology from an Empirical Standpoint, is that drawing introspective attention to one's current conscious experience may modify its phenomenology. Failing to take phenomenal modification into account affects the adequacy of extant versions of the acquaintance view. The purpose of this paper is to develop a better version, the integration account, that meets the phenomenal modification challenge while preserving the merits of other versions.
\end{abstract}

In this paper, I develop an account of the metaphysics of introspection of phenomenal states (or phenomenal-state introspection). The account I propose is a version of the acquaintance view, according to which introspecting a current phenomenal state involves bearing to it the relation of introspective acquaintance. My purpose here is not to defend the existence of acquaintance, or the superiority of the acquaintance view over other theories of introspection. Rather, assuming introspective acquaintance's psychological reality, I aim to develop a better and more refined version of the acquaintance view.

I will show that extant versions of the acquaintance view fail to explain an important fact about introspection, namely that drawing introspective attention to a current experience of one's may modify its phenomenology. I call this the phenomenal modification problem. The problem was articulated by Franz Brentano in his Psychology from an Empirical Standpoint and is at the origin of his famous distinction between inner perception and inner observation. It also played a crucial role in experimental psychologists' treatment of introspection until the first decades of the $20^{\text {th }}$ century. However, most contemporary theorists of introspection and self-knowledge seem to neglect the problem, and acquaintance theorists are no exception.

I will argue that any satisfactory theory of the nature of introspective acquaintance must take the phenomenological effects of attention into account. The bulk of the paper will be devoted to developing what I call the integration account of introspective acquaintance. I take this to be a better version of the acquaintance view because, while preserving the merits of other versions, it also meets the phenomenal modification challenge.

In $\$ 1$, I explain what phenomenal-state introspection involves, and how it is accounted for by extant versions of the acquaintance view. In $\$ 2$, I present the phenomenal modification problem, mainly by appeal to Brentano's articulation of it. In $\$ 3$, I provide an analysis of the effects of introspective attention on the phenomenology. In $\$ 4, I$ argue that extant versions of the acquaintance view fail to meet the phenomenal modification challenge. Finally, in $\$ 5$, I develop my own account of the metaphysics of introspective acquaintance, the integration account. 


\section{Introspective acquaintance}

Acquaintance is an epistemically significant relationship, typically spelled out in terms of direct awareness, where the relevant directness is both epistemic and metaphysical (Gertler 2011). ${ }^{1}$ Acquaintance is epistemically direct in that, by being acquainted with $x$, a subject $S$ gets an epistemic access to $x$ which is non-inferential, i.e., does not depend on $S$ 's having epistemic access to anything else (in particular, it is independent of $S$ 's entertaining any judgment). It is metaphysically direct in that, when $S$ is acquainted with $x$, no state or process mediates between $x$ and $S$ 's awareness of $x$. The notion of metaphysical directness is admittedly in need of elucidation-I am going to expand on this later on.

Neglected for much of the second half of the $20^{\text {th }}$ century, the notion of acquaintance, made popular by Bertrand Russell $(1910,1912)$, has progressively regained momentum over the last twenty years and has become increasingly prominent in philosophical areas as different as philosophy of mind, epistemology, philosophy of language, and metaphysics (see Knowles and Raleigh 2019 for a recent collection dedicated to acquaintance). ${ }^{2}$ It has figured in some responses to Frank Jackson's (1982) knowledge argument against physicalism (Bigelow and Pargetter 1990, 2006; Conee 1994; Levine 2019; Grzankowski and Tye 2019) it plays a key role in contemporary defenses of foundationalism about epistemic justification (Fales 1996; BonJour 2000, 2003; Fumerton 1996, 2001, 2009; Hasan 2013); it is appealed to in some prominent accounts of direct reference (Campbell 2002, 2019; Recanati 2010); it is explicitly used by several proponents of naïve realism about perceptual experience; ${ }^{3}$ it has recently been appealed to for explaining the nature of consciousness (Williford 2015); finally, it has been used to account for the nature of (a special kind of) introspective knowledge (Gertler 2001, 2012; Chalmers 2003; Pitt 2004; Horgan and Kriegel 2007; Balog 2012). It is this last usage of the notion that is relevant to our present purpose.

In particular, the focus of this paper is phenomenal-state introspection, the distinctively firstpersonal process through which one can acquire knowledge of (or at least form justified judgments about) the phenomenology of one's own current conscious experience. All and only the subject's current conscious mental states endowed with phenomenology (those there is something it is like for the subject to have) are eligible targets of phenomenal-state introspection. ${ }^{4}$ Unconscious states and past (or future) experiences cannot be introspected in this sense. The unpleasant character of your pain, the greenish character of your visual experience of the grass, the way you feel when you are angry, elated, or surprised are all potential targets of phenomenal-state introspection. ${ }^{5}$

To be introspected, an experience must not only be conscious but also attended to. Introspecting involves acquiring information about (some aspects of) one's current experience, which requires

\footnotetext{
${ }^{1}$ The epistemic significance of acquaintance is often taken to consist, at least, in its yielding a special kind of knowledge, namely knowledge by acquaintance.

${ }^{2}$ See also Thomas Raleigh (2019) for an excellent introduction to the notion of acquaintance: its origin, its puzzles, and its role in contemporary debates.

3 Among these are Campbell (2002), Hellie (2010), Brewer (2011), and Soteriou (2013) (cf. Raleigh 2019).

${ }^{4}$ Some philosophers (Rosenthal 2005; Carruthers 2005) think that there can be unconscious phenomenal states. If there are, they are not potential targets of phenomenal-state introspection as I characterize it here.

5 The scope of phenomenal-state introspection partly depends on which conscious mental states have phenomenology. One example concerns cognitive states such as thoughts, judgments, and occurrent beliefs. Whether these states can be the target of phenomenal-state introspection depends, at least partly, on one's stance about the existence and nature of cognitive phenomenology. Here I remain neutral about this point. For those who believe that there is cognitive phenomenology, what I say will apply to cognitive states too.
} 
drawing and sustaining attention toward it. ${ }^{6}$ Imagine you have a quite intense stomachache, but you keep working despite it. Arguably, although your stomachache experience is conscious (the pain does not disappear), you can divert your attention from it while focusing on your work. ${ }^{7}$ When you decide to go and see a doctor, and she asks you to describe what the stomachache feels like, you cannot answer unless you attend to the stomachache experience: you need to focus your attention on the experience to get the relevant information about its phenomenology and report it to the doctor. Such information was not available to you in the same way when most of your attentional resources were absorbed by your work. ${ }^{8}$ Phenomenal-state introspection is thus a process involving an effortful and voluntary activity on the part of the subject, where a central role is played by attention to the experience's phenomenology.

An account of the nature of phenomenal-state introspection is an account of the relationship between the introspective state (i.e., the mental state the subject is in in virtue of engaging in the introspective activity) and the introspected state (the phenomenal state which is the target of the introspective act of attention). Note that the introspective state is itself a conscious state with phenomenology. When you draw your attention to the pain sensation in your stomach, you enter an introspective state that has a certain phenomenology, one aspect of which is the awareness of painfulness. Therefore, in phenomenal-state introspection, the introspective state is itself a phenomenal state.

As noted, acquaintance is a relationship which is metaphysically direct. Acquaintance views of introspection typically explain the metaphysically immediate relationship of introspective acquaintance in terms of constitution (BonJour 2000; Gertler 2001, 2012; Chalmers 2003; Pitt 2004; Horgan and Kriegel 2007; Balog 2012): the introspective state is (partly) constituted by the introspected state. ${ }^{9}$ To appreciate this, compare the acquaintance view with its main competitor (as an account of the metaphysics of phenomenal-state introspection): ${ }^{10}$ the so-called inner sense view (Armstrong 1968; Lycan 1996). On the inner sense view, introspection is a kind of perception (where perception is accounted for in representationalist, rather than naïve realist, terms ${ }^{11}$ ). On a representationalist view of perceptual experience, when you visually perceive, say, a lemon, you have a visual representation of the lemon. The lemon and your visual representation of it are distinct existents merely causally related: the lemon

\footnotetext{
${ }^{6}$ Regardless of the existence of unconscious attention, what matters to my purpose here is a kind of attention that makes information personal-level available, i.e. available to the whole person (rather than merely to one or more of its subsystems) for conscious and deliberate cognizing, reasoning, and action guiding, and is therefore conscious-on the assumption that personal-level phenomena are, at the very least, conscious phenomena ( $f f$. Kriegel 2012).

7 Some (e.g. Prinz 2011) would object that the stomachache experience cannot be conscious unless you attend to itattention is necessary for consciousness. Although I disagree (arguments against the necessity of attention for consciousness are put forward by Mole 2008 and Smithies 2011), my claim that attention is necessary for introspection can be accepted regardless of whether attention is also necessary for consciousness.

${ }^{8}$ Although some information about the phenomenology may be available to you simply in virtue of being peripherally aware of the experience (Kriegel 2009, Ch. 5).

${ }^{9}$ Whether the constitution is full or partial is often left unspecified.

${ }^{10} \mathrm{I}$ do not mean to imply that acquaintance and inner sense are the only plausible alternatives as accounts of introspection or self-knowledge in general, just that they are the most prominent competitors in a much narrower debate, i.e. the one about the metaphysical structure of introspection of phenomenal states. Other accounts may well be equally or more suitable when it comes to other aspects of introspection and self-knowledge. (See e.g. Byrne 2005 about introspection of beliefs; Moran 2001 and Cassam 2015 about self-knowledge of propositional attitudes such as beliefs, desires, and intentions; and Siewert 1998 about the distinctiveness of first-person reflection on both attitudes and experiences.)

11 Since, on naive realism, the relationship between the perceiving subject and the perceived object is acquaintance, arguably, by assuming a naïve realist account of perception, the inner sense view would collapse into the acquaintance view.
} 
can exist independently of your visually attending to it and your visual representation can occur even without the lemon (e.g., in hallucination), but if your perceptual experience is veridical, the lemon causes your visual representation. Analogously, on the inner sense view of phenomenal-state introspection, when you introspect a current pain sensation of yours, you form an introspective representation of your pain sensation. As before, the sensation and the introspective representation are distinct existents merely causally related: they can occur independently of each other and, in the good case, the sensation causes the introspective representation. A remarkable consequence of the inner sense view is that the introspective state can exist independently of there being any target phenomenal state. In other words, it allows for introspective hallucination.

In contrast, on the acquaintance view the introspective state and the introspected state are neither causally related nor ontologically distinct. Rather than causal, the relationship between them is constitutive: the introspected state partly constitutes the introspective state. Accordingly, the introspective and introspected states are not independent of one another. Even if the target phenomenal state can exist independently of the introspective state (your pain sensation may exist unattended), the introspective state's existence depends on that of the target state: being partly constituted by it, your pain introspection can only exist if the pain does.

To that extent, on the acquaintance view there are not two distinct states, the introspective and the introspected, but rather one single introspective state, which is partly constituted by the introspected state. Brie Gertler (2001), who provides a particularly rigorous and detailed analysis of the metaphysics of acquaintance, spells out this constitutive relationship partly in terms of what she calls embedding: the introspective state embeds the introspected state, where a mental state $a$ is embedded in a mental state $b$ iff (i) if $b$ is present, $a$ must be present too, and (ii) $a$ can be present even if $b$ is not present. ${ }^{12}$ The idea is that when you introspect the pain sensation in your stomach, the pain sensation (partly) constitutes your introspective state. Arguably, this entails that the phenomenology of your introspective state is (partly) constituted by the phenomenology of the pain sensation. In the absence of any sensation, you could not be in this introspective state-as per (i). However, the existence of the pain sensation does not depend on its being introspected-as per (ii). This is intuitive: the pain sensation you now introspect existed (or at least could have existed) before your introspecting it and, plausibly, it could continue to exist after you cease attending to it. More generally, phenomenal states do not need to be introspected in order to exist.

Unlike the inner sense view, the acquaintance view is consistent with what strikes me as an important fact about introspection, namely that there cannot be introspective hallucination: it cannot be the case that it introspectively seems to one that one has a certain phenomenal state but no phenomenal state at all is present. ${ }^{13}$ To be sure, this claim is controversial, ${ }^{14}$ but acquaintance theorists tend to see this is a strength of their approach. What I want to consider next is an apparent weakness of the acquaintance view.

\footnotetext{
${ }^{12}$ Embedding is not the only condition that must be satisfied in order to have phenomenal-state introspection on Gertler's account. It must also be the case that (a) the introspective state refers to the introspected state and (b) it is in virtue of the embedding relationship that the introspective state refers to the introspected state.

${ }^{13}$ Nota bene: this does not entail the impossibility of introspective illusion, i.e., the case in which introspection misattributes properties to a phenomenal state that is actually there.

${ }^{14}$ So-called illusionists about phenomenal consciousness, for example, maintain that we undergo introspective hallucinations throughout all our awaken life. See e.g. Dennett (1988), Frankish (2016), and Kammerer (2016).
} 


\section{The phenomenal modification problem}

A potential challenge to any account of the nature of introspection is what I call the phenomenal modification problem. The problem was famously articulated by Franz Brentano:

In observation, we direct our full attention to a phenomenon in order to apprehend it accurately. But with objects of inner perception this is absolutely impossible. This is especially clear with regard to certain mental phenomena such as anger. If someone is in a state in which he wants to observe his own anger raging within him, the anger must already be somewhat diminished, and so his original object of observation would have disappeared. The same impossibility is also present in all other cases. It is a universally valid psychological law that we can never focus our attention upon the object of inner perception. (Brentano 1874, p. 30)

On Brentano's view, introspection destroys its own target. The intentional, effortful, and voluntary act of focusing one's attention on a current phenomenal state of one's modifies the phenomenology of that phenomenal state and thereby alters its original target. Introspection, thus, is self-defeating and thereby impossible.

This line of argument against introspection was not unfamiliar in Brentano's time. Kant had already expressed a similar worry with respect to the possibility of developing a 'science of the soul', for in inner observation, he wrote, 'the observation itself, alters and distorts the state of the object observed' (Kant 1786/1883, 'Preface', pp. 141-142). Similarly, part of Auguste Comte's invective against introspection was the idea that self-observation is impossible because attending to one's current experience modifies and thereby destroys it (Comte 1830, 'Premiere Leçon', p. 105). A century later, the same critique was still part of Gilbert Ryle's attack to privileged introspective access (Ryle 1949, Ch. 6, p. 147).

Throughout the $19^{\text {th }}$ century and until the first decades of the $20^{\text {th }}$ century, any philosopher or psychologist who wanted to defend the possibility of a scientific study of the mind, or provide an account of the nature of introspection, had to face up to the phenomenal modification problem. Brentano himself dealt with the problem by distinguishing inner observation (which involves attentive, focal awareness of a current phenomenal state) from inner perception, a kind of awareness of one's current phenomenal state which is merely peripheral and not attentive. Only inner perception, claims Brentano, can constitute the grounding method of psychology.

Early introspectionist psychologists were also concerned with phenomenal modification. Pioneer experimental psychologist Wilhelm Wundt was motivated by the same worry as Brentano:

The chief problem of psychology, however, is the exact observation of the rise and progress of subjective processes, and it can be readily seen that under such circumstances the intention to observe either essentially modifies the facts to be observed, or completely suppresses them. (Wundt 1897, p. 21).

Like Brentano, Wundt rejected attentive self-observation as a legitimate method for collecting scientific data and maintained that the only reliable psychological method is inattentive internalperception. Edward Titchener, Wundt's student and most prominent introspective psychologist of his days, faced the phenomenal modification challenge partly by privileging retrospection (i.e. memory of immediately past experiences) over introspection. He also tried to downplay the phenomenal modification challenge through a number of arguments (see Titchener 1912a, pp. 442-444 and 1912b, p. 493). William James was also sensitive to the modification problem. In Chapter VII of The Principles of Psychology, he raises 
the problem by quoting Comte (1830) and (similarly to Titchener) suggests a solution in terms of retrospection, partly by quoting John Stuart Mill (1882). He writes:

But the psychologist must not only have his mental states in their absolute veritableness, he must report them and write about them, name them, classify and compare them and trace their relations to other things. Whilst alive they are their own property; it is only post-mortem that they become its prey. [...] Comte is quite right in laying stress on the fact that a feeling, to be named, judged, or perceived, must be already past. No subjective state, whilst present, is its own object; its object is always something else. (James 1890, pp. 189-90)

Surprisingly, what worried these thinkers so much has, with few exceptions, disappeared from the agenda of contemporary theories of introspection and self-knowledge. But the problem itself has not disappeared, of course, and one of my goals here is to show that it can do important dialectical work, namely, by bringing out the inadequacy of many extant accounts of introspection.

\section{Effects of attention on the phenomenology}

It is useful to the distinguish two kinds of attentional effects on phenomenology. One is the way attending to different objects of experience affects the experience's phenomenology; the other is the way attending to the experience itself affects its phenomenology. The former concerns the effects of 'extrospective' attention on phenomenology, the latter the effects of introspective attention. Although only the second is relevant to the phenomenal modification problem, it is useful for a comprehensive appreciation of attention's relevance to phenomenology to consider both kinds of attentional effects.

The effects of conscious attention on the phenomenology of experience have been studied by Uriah Kriegel (2009, Ch. 5) and, more recently and more thoroughly, by Sebastian Watzl (2017, Ch. 8 and Ch. 9). Consider the auditory experience you have when you listen to a jazz concert. ${ }^{15}$ You may first enjoy your musical experience in its totality, and have your attention roughly equally distributed across all the instruments. You may then focus your attention on the sound of the saxophone and, later, shift it to the sound of the piano. Intuitively, the attention shift makes a difference to the phenomenology of your auditory experience. The way it is like for you to listen to the music changes partly depending on what you attend to. Or consider a meditation session in which you are asked to focus on different parts of your body in turn. You attend to your feet, then to your ankles, your knees, your pelvis, and so on. Again, each shift of attention implies a phenomenological change.

That attention makes a phenomenological difference seems intuitively true. ${ }^{16}$ However, how attention affects the phenomenology is not straightforward to spell out. One general effect seems to be this: attended things appear clearer, more defined, than unattended ones. One way to spell this out is in terms of determinable vs. determinate properties (Watzl 2017, pp. 168-69). ${ }^{17 ; 18}$ The idea is that attention affects how determinate things look. By attending to a certain feature, one discerns it in a finer-

\footnotetext{
15 The music example is put forward by both Kriegel and Watzl.

16 Watzl (2017, p. 155) claims that that attention affects the phenomenology of experience is even 'uncontroversial'. I think that his claim is a bit too strong though.

17 Watzl refers to the work of Nanay (2010) and Stazicker (2011) for an account along these lines. These philosophers take experience of more determinate properties to be what constitutes the phenomenology of attention. However, we need not accept such a strong view here: for the present purpose it is sufficient to note that experience of more determinate properties is one possible phenomenological effect of attention.

18 As for the determinable-determinate relationship consider the following: red is a determinate of the determinable color; crimson is a determinate of the determinable red.
} 
grained way. When you attend to a leaf on a tree, its features (color, shape, size) are experienced by you more determinately than those of the unattended leaves. When you attend to the saxophone sound at the jazz concert, the sound appears more determinately to you than when you do not attend to it: among other things, you can distinguish its pitch and timber in a finer-grained way. Similarly, when you attend to a certain part of your body, you proprioceptively experience some of its features (shape, weight) more determinately than you do unattended body parts.

Another effect attention sometimes has on the phenomenology is modification of the intensity of experience. At the jazz concert, shifting your attention to the sound of the saxophone may make it sound a bit louder to you. At the meditation session, drawing your attention to your right foot may make it appear a little heavier to you.

As both Kriegel (2009) and Watzl (2017) observe, the effect of attention on the phenomenology is not limited to modifying the way things appear to the subject-it is not limited to modifying the qualitative aspects of one's experience in the ways specified above. Perhaps the most fundamental phenomenological effect of attention is its shaping the experience's structure, notably its foreground/background structure. This has a direct effect on salience: the more foregrounded an element of experience, the more salient it is. Thus, when you shift the focus from the sound of the saxophone to that of the piano, the overall experience acquires a new configuration such that the piano occupies the center of your phenomenal field and thereby becomes more salient, while the sax becomes recedes into the background. The less salient aspects of your experience do not lie on one single flat background level: the background is itself structured. The sound of the sax, as that of the other instruments, is experienced as more salient than, say, the pain in your stomach, perhaps because they are closer, in terms of relevance, to the sound of the piano. Attention thus organizes the center/periphery structure of the experience in such a way that different aspects of the overall phenomenology may acquire different levels of prominence. Attention provides experience with 'phenomenal depth', so to speak.

Some of the cited phenomenological effects of attention on perceptual appearances are contingent. ${ }^{19}$ But shaping the experience's center-periphery structure occurs at every instance of attention focusing or shifting: it is a (nomologically) necessary phenomenological effect of attention. Whenever one attends to a certain object, it becomes more experientially salient, while other objects become less salient.

So far we have considered the effects of extrospective attention on phenomenology. But similar effects attend introspective attention. Thus, every time one introspectively attends to a certain phenomenal state, such phenomenal state becomes more salient (in some cases, it may become the most salient aspect of one's phenomenal field). Moreover, at least sometimes, introspective attention also modifies some appearance properties (i.e. properties associated with how things appear to the subject in experience). It may modify its intensity, as when introspecting a pain sensation makes it more painful. It may modify its clarity: introspectively attending to a phenomenal state may render its phenomenology more determined and defined. Since any attention shift entails a change in the foreground/background

\footnotetext{
19 As mentioned above, people like Nanay and Stazicker think that the phenomenology of attention is exhausted by increased clarity (understood as experience of more determinate properties). If they are right, then change in clarity is a (nomologically) necessary effect of attention on the phenomenology. Some may also argue that any instance of attention focusing or shifting entails a (however slight) intensity modification. Watzl (2017, pp. 171-181) develops two arguments against the view that the phenomenological effect of attention reduces to change in appearance properties. As I point out in the next paragraph, I remain neutral on whether the change in phenomenology associated with salience reduces to change in some appearance properties (clarity, determinacy, intensity or else).
} 
structure and thereby a change in salience, any introspective act entails a change in the target phenomenal state's salience, sometimes at the expense of external objects. If you are angry at a rude cashier, and then shift your attention from the cashier to your anger, the cashier's rudeness will lose in experiential prominence while the anger-ish quality of your experience will become more salient to you.

As with extrospective attention, some effects of introspective attention on phenomenology may well be contingent. Attending to one's pain sensation tends to make it more painful, but taking a step back from one's anger in order to introspect it tends to make one less angry. And some experiences (e.g., some color experiences) may undergo no change in intensity when introspected. However, introspective attention's salience-related effects seem (nomologically) necessary: when you shift attention from one aspect of your current experience to another, the first gains in salience while the second recedes. In consequence, every introspective act entails some phenomenal modification, namely, the phenomenal modification associated with increased salience.

It follows that whenever introspected, a phenomenal state undergoes some phenomenal change. The phenomenology of the target state is not the same before and while being introspected: some aspects of it (at a minimum, those associated with salience) change upon its being introspected. A surprising consequence is that the target state's post-change salience-related phenomenal features depend on the introspective state. ${ }^{20}$ This is because certain phenomenal features of the target can only be present when it is introspected. Therefore, the target phenomenal state, qua modified by the introspective activity (i.e. with all the phenomenal features it possesses while being introspected), is not phenomenally the same as it would be independently of the introspective state. Note well: the claim here is not that a phenomenal state of the same kind could not exist independently of being introspected. Nor is the claim that, for any phenomenal state $\varphi$ with a certain (sufficiently high, or maximal) degree of salience, $\varphi$ can only exist if introspected. Rather, the claim is that, when a token phenomenal state is introspected, that token phenomenal state would not have been the same-at the very least, it would not have been as salient-independently of the relevant introspective state. To spell this out, consider two phenomenal states $\varphi_{1}$ and $\varphi_{2}$ both instances (tokens) of the same phenomenal-state type $\Phi$, which is highly or maximally salient; $\varphi_{1}$ is introspected by its subject, while $\varphi_{2}$ is not. Both $\varphi_{1}$ and $\varphi_{2}$ are highly or maximally salient, but while $\varphi_{1}$ is salient in virtue of being the target of introspective activity, $\varphi_{2}$ is salient for some other reason (e.g. all other phenomenal states co-occurring with it suddenly decrease in intensity, so that $\varphi_{2}$ becomes the most intense and thereby the most salient). My claim is that, as far as $\varphi_{1}$ is concerned, the counterfactual "if $\varphi_{1}$ was not currently being introspected, other things being equal, it would still be just as salient" is false. ${ }^{21}$

A satisfactory account of the nature of phenomenal-state introspection should take this phenomenon into account. Not only should it accommodate the possibility of phenomenal modification, it should also (1) account for the fact that such phenomenal modification occurs in every instance of introspection and, ideally, (2) explain how introspection is possible despite this. ${ }^{22}$

\footnotetext{
${ }^{20}$ The dependence here is constitutive, rather than causal. Perhaps causal dependency may feature in an inner-sense picture, where the introspective state and the target are distinct and causally related. In the acquaintance framework, however, dependence is constitutive.

21 This way of spelling out the point heavily relies on a suggestion from an anonymous referee from EJP.

22 Thanks to Farid Masrour for making point (2) clear to my mind.
} 


\section{The inadequacy of extant acquaintance accounts}

As it stands, the acquaintance account does not seem to meet the phenomenal modification challenge: it does not have the resources to explain the phenomenal change undergone by the target phenomenal state. As noted, the post-change phenomenal state is ontologically dependent on the introspective state. Therefore, not only the introspective state depends on the introspected state; there is an important sense in which the introspected state, once introspected, depends on the introspective state as well. The introspective state and its target are thus interdependent. This interdependence is not accommodated in extant acquaintance accounts.

As noted, extant acquaintance accounts imply that the introspected state can exist independently of the introspective state. Although this captures an important intuition about introspection-namely that a phenomenal state may exist before and continue to exist after (and therefore independently of) being introspected-it fails to account for the idea that the post-change phenomenal state depends on the introspective state.

It might be objected that while the introspective state depends on the introspected state ontologically, the introspected state depends on the introspective state merely causally: in modifying its target, the introspective state causes a change in the introspected phenomenal state, and to that extent brings about the post-change state's occurrence. However, while this response is plausible for such contingent attentional effects as changes in intensity, it is implausible for the necessary attentional effects involving changes in salience. For the relative salience of a phenomenal feature consists in its being focally introspected-it is not simply brought about by it.

To be clear, I am not claiming that extant acquaintance views are incompatible with phenomenal modification. Recall, however, that to meet the phenomenal modification challenge, a theory of the metaphysics of phenomenal-state introspection must not only be consistent with phenomenal modification. It must also explain (1) the fact that such phenomenal modification occurs every time one introspects and (2) how introspection is possible notwithstanding phenomenal modification. What extant acquaintance accounts lack is an explanation of (1) and (2).

In the next section, I develop a novel version of the acquaintance view that I claim can explain phenomenal modification - a version that accounts for the fact that the introspected phenomenal state, qua modified by the introspective activity, depends on the introspective state. At the same time, the account will capture the intuition (as the other versions of the view do) that phenomenal states can exist independently of being introspected.

\section{A proposed solution: the integration account}

In setting up the foundations for the integration account, I will make some substantive assumptions about the metaphysics of mind. My thesis is that if these assumptions are true, the integration account is a promising account of phenomenal-state introspection. However, I do not claim that the integration account is the sole satisfactory account; equally satisfactory alternatives may be pursued on different assumptions.

As a version of the acquaintance view, the integration account entails that there is a relationship of constitutive dependence between the introspective state and its target. Whereas extant acquaintance accounts posit unilateral dependence (the introspective state depends on its target, but 
the target is independent of the introspective state), though, the integration account posits bilateral or inter-dependence: once introspected, the target depends on the introspective state too.

The view is roughly this. Once introspected, the target state becomes a proper part of the introspective state. In virtue of this, some of its phenomenal properties are inherited by the introspective state. In addition, however, some of the phenomenal properties that the target state has once it is introspected depend on the introspective state. This explains the phenomenon of phenomenal modification.

To make the account more precise and clarify its explanatory power, some set-up is in order. In \5.1 I lay out the assumptions on which the integration account is based. In \$5.2 I articulate a more precise and more explanatory formulation of the view.

\subsection{Preliminary assumptions}

5.1.1. The ontological status of phenomenal states. In thinking about the metaphysics of phenomenal-state introspection, it may be helpful to specify what kind of entity we have in mind when we talk about phenomenal states. There are at least two options. First, a phenomenal state may be seen as a particular, a bearer of phenomenal properties (call this the Particular View). Accordingly, a pain sensation is characterized as a particular having the phenomenal property associated with pain ("phenomenal painfulness'). Second, a phenomenal state may be described as a Kimean event (Kim 1993), i.e. the instantiation of a phenomenal property by a subject at a time (Kimean View). Here your present pain sensation is characterized as the instantiation of phenomenal painfulness by you (the subject) now. ${ }^{23}$

All I say in what follows can fit both views. I will often talk as if phenomenal states are particulars (bearers of phenomenal properties), mostly for expository reasons. ${ }^{24}$

5.1.2. Kinds of phenomenal properties. Phenomenal states have properties, some of which are phenomenal (e.g. reddishness, painfulness) and other non-phenomenal (e.g. occurring on Tuesday). Phenomenal properties come in three kinds: qualitative, quantitative, and relational.

Qualitative phenomenal properties are phenomenal properties such as reddishness, bluishness, painfulness, burning painfulness, stabbing painfulness, and so on. They define the qualitative aspect characterizing each kind of phenomenal state: they are what constitutes the difference between, say, an experience of redness and an experience of blueness (or between an experience of saxophone sound and an experience of stabbing pain). Intuitively, two qualitatively different phenomenal states (phenomenal states with different qualitative phenomenal properties) are phenomenal states of different kinds.

Quantitative phenomenal properties are properties in virtue of which qualitative phenomenal properties are modulated. Each dimension of phenomenal variation is associated with a quantitative phenomenal property. Quantitative phenomenal properties can be quantified: for any quantitative phenomenal property $Q$, a phenomenal state $\varphi$ that can be $Q$ can be more or less $Q$. They are phenomenal because they make a difference to the phenomenology of one's experience. Intensity is a paradigmatic example. A pain sensation may be more or less painful: when you stub your toe on the couch, you

\footnotetext{
${ }^{23}$ There are surely other options to be explored, but the ones mentioned here strike me as the theoretically most interesting.
} ${ }^{24}$ When needed, I will specify how the account can be adjusted to fit the different views. 
have a sudden excruciating pain sensation, which gradually diminishes. The sensation, initially extremely intense, becomes less intense as time passes. Other kinds of phenomenal state vary in intensity: a visual experience may be more or less bright, an auditory experience more or less loud, an itchy experience more or less itchy, an anger experience more or less intense, and so on. Clarity (in the sense of definiteness spelled out in \$3) may also be numbered among the quantitative phenomenal properties. As long as a phenomenal state can be phenomenally more or less determinate, its clarity or definiteness is a phenomenal property that can be quantified. Given that a phenomenal state can be more or less salient, salience may also be considered a quantitative phenomenal property. Whether it really is partly depends on whether a phenomenal state's salience can be measured only relatively to other phenomenal states $\left(\varphi_{1}\right.$ is more salient than $\left.\varphi_{2}\right)$ or there is also an absolute measure of salience $\left(\varphi^{\prime} s\right.$ degree of salience is $n$ ). With intensity, for example, not only a phenomenal state can be more or less intense than another: one can also establish a scale, say from 1 to 10, such that a phenomenal state can be said to have a certain degree of intensity within that range. If a similar scale can be established for salience, then salience may legitimately be considered as a quantitative phenomenal property.

Both qualitative and quantitative phenomenal properties are non-relational properties. Relational phenomenal properties are phenomenal properties phenomenal states have in virtue of bearing certain relations to other phenomenal states. Some of them are: phenomenal unity $\left(\varphi_{1}\right.$ is unified with $\varphi_{2}, \varphi_{3}, \ldots$, and $\left.\varphi_{n}\right)$, phenomenal parthood $\left(\varphi_{1}\right.$ is part of the same whole as $\varphi_{2}, \varphi_{3}, \ldots$, and $\left.\varphi_{n}\right)$, phenomenal simultaneity/precedence $\left(\varphi_{1}\right.$ is [experienced] before $\left.\varphi_{2}\right)$, and comparative salience $\left(\varphi_{1}\right.$ is more/less salient than $\varphi_{2}$ ). Relational phenomenal properties are phenomenal because they make a difference to the phenomenology. Phenomenal states $\varphi_{1}$ and $\varphi_{2}$ which are part of the same overall experience are not only unified, but also experienced as unified: not only there is something it is like to have $\varphi_{1}$ and something it is like to have $\varphi_{2}$-there is also something it is like to have $\varphi_{1}$ and $\varphi_{2}$ together (Bayne 2010: 11). As for salience, we have already seen in $\$ 3$ that difference in salience makes a phenomenal difference: $\varphi_{1}$ 's phenomenology is different when $\varphi_{1}$ 's is more salient than $\varphi_{2}, \varphi_{3}$, and $\varphi_{4}$, from when it is as salient as $\varphi_{2}, \varphi_{3}$ and less salient than $\varphi_{4}$. The phenomenology of your experience of the saxophone is different when the sound of the saxophone is the most salient aspect of your phenomenal field than when the sound of the piano is the most salient aspect.

One plausible view, which I nonetheless will not argue for, is that qualitative phenomenal properties are first-order phenomenal properties, whereas quantitative and relational phenomenal properties are second-order phenomenal properties- properties of phenomenal properties. ${ }^{25}$

If phenomenal states are particulars, as per the Particular View, then they are bearers of quantitative, qualitative, and relational phenomenal properties. If phenomenal states are Kimean events, then at least two options suggest themselves. On the first option-call it the True-Kimean View - a phenomenal event consists in the subject's instantiating a certain qualitative phenomenal property. Quantitative and relational phenomenal properties are properties of phenomenal events: they are properties of instantiations of qualitative phenomenal properties. ${ }^{26}$ This option is consistent with Jaegwon Kim's own conception that events have one constitutive property (which, together with the object which instantiates it and the time at which the property is instantiated, individuates the

\footnotetext{
${ }^{25} \mathrm{I}$ am indebted to Takuya Niikawa for suggesting this to me.

${ }^{26}$ Of course, there are further options in the logical space: that phenomenal events are instantiations of quantitative phenomenal properties (qualitative and relational phenomenal properties are properties of phenomenal events), and that phenomenal events are instantiations of relational phenomenal properties (qualitative and quantitative phenomenal properties are properties of phenomenal events). These options, though, do not seem worth considering.
} 
relevant event) but can themselves exemplify several properties (Kim 1993, Ch. 3). ${ }^{27}$ It also goes well with the idea that qualitative phenomenal properties are first-order, whereas quantitative and relational phenomenal properties are second-order. On the second option-call it the Pseudo-Kimean Viewphenomenal events are co-instantiations of several phenomenal properties, including quantitative and relational, by a subject at a time. Here quantitative and relational phenomenal properties are also constitutive: they contribute to the individuation of phenomenal events.

5.1.3. Essential vs. accidental properties. Some of a phenomenal state's properties are essential to it, others accidental. Notwithstanding its well-known problems (Fine 1994), the modal characterization of essential and accidental properties will suffice for present purpose. Roughly, essential properties are properties something must have-without its essential properties, it could not exist. Accidental properties are properties something has, but could have lacked. However, you may plug your preferred characterization of essential and accidental properties into my account, provided it entails the modal characteristics just presented.

I am assuming that at least some objects have some of their properties essentially, where this implies that, for some $\mathrm{x}, \mathrm{x}$ has some property $\mathrm{F}$ necessarily (i.e. $\mathrm{x}$ is necessarily $\mathrm{F}$ ). This is to be read as de re, rather than de dicto necessity: necessity is ascribed to $\mathrm{x}$ (the object) itself ( $\mathrm{x}$ has the property of being necessarily F) rather than to the proposition ' $\mathrm{x}$ is $\mathrm{F}$ ' (it is necessarily true that $\mathrm{x}$ is $\mathrm{F}$ ). While the truth of a statement ascribing de dicto necessity to a proposition depends on how objects featuring in it are thought of, the truth of a statement describing de re necessity to an object does not depend on how that object is thought of. So, while the de-dicto-necessity-ascribing statement (1) "Necessarily, the number of planets in the Solar System is even" is false (though (2) "Necessarily, eight is even" is true), the de-re-necessity-ascribing statement (3) "The number of planets in the Solar System is necessarily even" is true (as is (4) "Eight is necessarily even"). The truth value of (1) and (2) depends on how the number eight is thought of (as the number of planets in the Solar System, or just as the number eight). The truth value of (3) and (4) does not depend on how the number eight is thought of: being necessarily even is attributed to the number eight (the object itself) in both sentences, regardless of how the number is thought of. Accordingly, objects have their essential properties (de re) necessarily, regardless of how they are thought of.

All phenomenal states have some essential properties. For any phenomenal state $\varphi$, there is some property $F$ such that $\varphi$ has $F$ essentially; if so, then $\varphi$ is necessarily $F$ (and it is so independently of how it is thought of). The essential properties of a phenomenal state $\varphi$ are thus properties it must have: if it did not have them, $\varphi$ would not exist. The accidental properties of a phenomenal state $\varphi$ are properties that $\varphi$ has but could have lacked. Importantly, a phenomenal state is individuated by its essential properties: $\varphi$ and $\psi$ are the same phenomenal state iff $\varphi$ and $\psi$ have exactly the same essential properties. Therefore, even if a phenomenal state's accidental properties change, it remains the same state.

Which of a phenomenal state's properties are essential to it, and which are accidental? A preliminary question may concern whether only phenomenal properties, or instead also some non-

\footnotetext{
27 The view is consistent with Kim's conception if, for any phenomenal state $\varphi$, there is just one qualitative phenomenal property which individuates $\varphi$.
} 
phenomenal properties, can be essential to a phenomenal state. ${ }^{28}$ However, as will become clear in the next subsection, our present interest is somewhat independent of whether some (and, if, so, which and how many) non-phenomenal properties are essential to a phenomenal state. For what we are concerned with, in developing an account of the metaphysics of introspective acquaintance, are the phenomenal properties of phenomenal states. Our interest, after all, is in phenomenal-state introspection and, in particular, introspection of the phenomenology of phenomenal states. Therefore, what is crucial here is which phenomenal properties are essential to a phenomenal state: different assumptions in this respect will lead to different accounts of the metaphysics of introspective acquaintance. Here are some relevant options:

(a) All of a phenomenal state's phenomenal properties are essential.

(b) Among the phenomenal properties, all and only the non-relational (i.e. qualitative or quantitative) phenomenal properties are essential.

(c) Among the phenomenal properties, all and only the qualitative phenomenal properties (i.e. all its non-relational and non-quantitative phenomenal properties) are essential.

(d) Some but not all qualitative phenomenal properties are essential and all non-qualitative phenomenal properties are accidental.

The list is not exhaustive - these are just the options that strike me as most relevant. ${ }^{29}$ Crucially, here I assume that (c) is true: all and only its qualitative phenomenal properties are essential to a phenomenal state- the quantitative and the relational phenomenal properties are accidental. On this view, the painful aspect of the pain sensation in your stomach — phenomenal painfulness - is essential to it. Its intensity, by contrast, is not essential (it is accidental). Intuitively, you have a stomachache experience that is getting worse and worse, not a fast-paced succession of innumerably many shortlived stomachaches each supplanting a vanishingly weaker one. Similarly, the property of, say, being unified with children-hearing and chocolate-tasting and the property of occurring after a visual experience of a sheet of paper are accidental to your stomachache; it would be the same experience even if unified with saxophone-hearing and gelato-tasting or occurring before a visual experience of a sheet of paper. ${ }^{30}$ Of course, this choice, though partly motivated by intuitions, is mostly stipulative (it is assumed here, rather than argued for). Alternative ways of individuating phenomenal states may be preferred by different theorists, which may lead to alternative accounts of the metaphysics of acquaintance. Here, I develop a model which presupposes option (c).

(Option (d) — that only some (but not all) qualitative phenomenal properties are essential — is consistent with most of what I will say below. Nonetheless, I am doubtful about this option. For one

\footnotetext{
${ }^{28}$ Plausibly, it is not the case that only non-phenomenal properties are essential to a phenomenal state: once you accept that phenomenal states have phenomenal properties, a view that entails that phenomenal properties play no role in the individuation of phenomenal states sounds pointless.

${ }^{29}$ For instance, I have not considered the option that all non-qualitative phenomenal properties are essential because it seems obvious enough to me that quantitative and relational phenomenal properties are not sufficient to individuate phenomenal states.

${ }^{30}$ How does this interact with different views about phenomenal-state ontology? Option (c) is compatible with all views considered in $\$ 5.1 .1$ and $\$ 5.1 .2$ except the Pseudo-Kimean View, on which phenomenal states are phenomenal events characterized as co-instantiations of qualitative, quantitative, and relational phenomenal properties. Accordingly, phenomenal states are individuated by all their qualitative, quantitative, and relational phenomenal properties. Therefore, on the Pseudo-Kimean View, not only qualitative phenomenal properties, but also quantitative and relational phenomenal properties are essential, which is inconsistent with (c). On the other hand, (c) fits particularly nicely with the True-Kimean View, according to which phenomenal states are phenomenal events characterized as instantiations of a qualitative phenomenal property (by a subject at a time) and thereby entails that phenomenal states are individuated by qualitative phenomenal properties.
} 
thing, it seems to me that any account on which only a subset of a phenomenal state's qualitative properties are essential would be somewhat arbitrary-there does not seem to be any matter of fact concerning which selection of qualitative phenomenal properties should be considered as essential.)

Although the substantive assumptions I make are not defended here, they are not chosen arbitrarily either. For these assumptions allow to meet the phenomenal modification challenge while making the minimal number of changes to the acquaintance account. Different assumptions would, arguably, require major modifications to extant acquaintance accounts_and potentially drifting away from their spirit. ${ }^{31}$

\subsection{Integration}

A satisfactory account of introspective acquaintance must meet the phenomenal modification challenge while doing justice to the intuition that phenomenal states can exist without being introspected, as well as make sense of the possibility of introspection. Extant acquaintance accounts, we have seen, fail to explain phenomenal modification. In their stead, I propose the integration account.

In phenomenal-state introspection, the relationship between the introspective state and the target phenomenal state is integration, where a phenomenal state $\varphi$ is integrated in a phenomenal state $\iota$ iff:

(i) $\varphi$ is a proper part of $\iota$;

(ii) $\iota$ inherits all of $\varphi$ 's essential properties;

(iii) (some of) $\varphi$ 's accidental phenomenal properties depend on ?;

(iv) $\imath$ refers to $\varphi$;

(v) $\iota$ refers to $\varphi$ partly in virtue of (i) and (ii).

As noted in $\$ 1$, not only the target, but also the introspective state is a phenomenal state-it is a conscious state with phenomenology. On the integration account of phenomenal-state introspection, the integrating state, $l$, is the introspective state and the integrated state, $\varphi$, is the target phenomenal state. ${ }^{32}$ In this account, clauses (i) and (ii) are shared with extant acquaintance views and are intended to capture the intuition that introspective hallucination is impossible. Meanwhile, clauses (iv) and (v) are simply intended to capture the idea that the introspective state is about the introspected state and that this is so partly in virtue of the mereological relationship between the two states (rather than reference being yielded through some indirect path)—-more on this momentarily. What is distinctive of the integration account is clause (iii). The fact that some of $\varphi$ 's phenomenal properties depend on $\iota$ is intended to explain the fact that phenomenal states are modified by being introspected, while the fact that the thus dependent properties are accidental explains why experiences can occur either introspected or not, as well as why introspection is possible.

Roughly, the idea is this. Once a phenomenal state is introspected, its phenomenal salience (i.e. the phenomenal property which is modified whenever introspection occurs) changes. This explains

\footnotetext{
${ }^{31}$ For instance, assuming (a) or (b) of the list of options above would imply that, at least sometimes, introspection does destroy the target phenomenal state. Since the phenomenal properties modified by the introspective act of attention (salience and, at least sometimes, intensity and clarity) are quantitative or relational, on those assumptions the introspective act of attention would modify some of the essential properties of the target. The resulting account would thus have to give up the idea that the target phenomenal state continues to exist upon being introspected.

32 Is there integration outside introspection? I cannot think of any other case in which (i) $-(\mathrm{v})$ are satisfied but where $\varphi$ and $\iota$ are not an introspected and an introspective state respectively. However, nothing in the account rules out the possibility of such a case.
} 
the nomological necessity of phenomenal modification. Importantly, however, salience, which is the aspect of the introspected state that ontologically (and not merely causally) depends on the introspective state, is among the target state's accidental properties. For as we have seen, it is either a relational phenomenal property (namely, if salience is always relative to other concurrent experiences and does not admit of an absolute magnitude) or at best a quantitative phenomenal property (namely, if salience can be quantified absolutely). Either way, it is not a qualitative phenomenal property, and therefore is accidental to the experience that has it—at least if, as I assume here, (c) or (d) are true. Moreover, the other phenomenal properties that might be modified by the introspective act-intensity and clarityare also accidental (they are quantitative phenomenal properties). This explains why the very same state modified by introspection could exist un-introspected: it is not one of its essential, individuating properties that is changed by introspection. It also explains the sense in which introspection is possible: it does not destroy its target, insofar as it does not make its target lose any of its essential properties, but merely modifies it, insofar as it makes it lose one or more of its accidental properties.

The remainder of this subsection is devoted to developing the integration account more thoroughly. Clause (i) of the account entails that, when $\varphi$ is integrated in $\iota, \imath$ is constituted by $\varphi$, although not fully constituted by it: there are parts of $\iota$ which are not parts of $\varphi$. Therefore, $\iota$ is not identical to $\varphi$, but is only partly constituted by $\varphi$.

That (ii) $\iota$ inherits all of $\varphi$ 's essential properties means that, when $\varphi$ is integrated in $\iota$, all of $\varphi$ 's essential properties are also i's essential properties, and this in virtue of $\varphi$ 's being part of $\iota$.

Although all of $\varphi$ 's essential properties are also i's essential properties, the reverse does not apply: there are some essential properties of $\iota$ which are not also essential properties of $\varphi$. For if, as we are assuming here, phenomenal states are individuated by their essential properties, if $\iota$ and $\varphi$ shared all their essential properties, $\iota$ and $\varphi$ would be identical-they would be the same state. But, on the integration account, $\iota$ and $\varphi$ are not the same state. For one thing, as noted, although $\varphi$ partly constitutes $\iota$, there are some parts of $\iota$ that are not parts of $\varphi$. For another, given that $\iota$ refers to $\varphi-$ as per condition (iv) - the two states must be at least conceptually distinct. Therefore, since the two states are not identical, there must be some essential properties of $\iota$ which are not also essential properties of the target phenomenal state. Spelling out which are the essential properties of $\iota$ that are not also $\varphi$ 's essential properties is not straightforward and exceeds our present purpose. The explanatory power of the integration account remains intact even if this specific question is left open.

As a consequence of (ii), ı cannot be present without $\varphi$ being also present: without $\varphi$, some of is essential phenomenal properties would not be present, therefore (since, recall, phenomenal states are individuated by their essential phenomenal properties) $\iota$ could not exist. The derivation runs roughly as follows: (P1) All of $\varphi$ 's essential properties $E$ are essential to ı. (P2) ı can instantiate E only if $\varphi$ is present (because $\iota$ has $E$ just in virtue of being partly constituted by $\varphi$ ). (P3) For any $\chi$, if $x$ did not instantiate some of its essential properties, $x$ would not exist. Therefore, if $\varphi$ were not present, then $\iota$ could not exist. ${ }^{33}$

\footnotetext{
33 One might have the following worry about (P1). (I owe this objection to an anonymous referee from EJP.) As noted in $\$ 1$, in phenomenal-state introspection, introspective states are themselves phenomenal states-they are conscious mental states with phenomenal properties. Since (as I assume here), for any phenomenal state, all its qualitative phenomenal properties are essential to it, (P1) implies that all $\varphi$ 's qualitative phenomenal properties are essential to $\iota$. However, phenomenal state tokens (including introspective states) may exemplify multiple types. Suppose $\varphi$ is a stomachache experience. The introspective state $\iota$ directed at it, besides being a phenomenal state whose qualitative phenomenal properties are those associated with stomachache, also exemplifies other kinds: it is, for example, an awareness of stomach distress, and it may also be part of one's motivation to take an antacid. Now, the objection goes, whereas i's qualitative phenomenal
} 
As per (iii), when $\varphi$ is integrated in $\iota$, some of $\varphi$ 's accidental phenomenal properties depend on $\iota$. Thus, were $\varphi$ not integrated into $l$, some of its accidental phenomenal properties would have been different.

Condition (iv) rules out cases in which (i), (ii), and (iii) are satisfied in the absence of introspection. For just conditions (i), (ii), and (iii) may be satisfied, for example, also by a phenomenal state and the overall experience to which it belongs. ${ }^{34}$ On some views of the unity of consciousness, a phenomenal state $\varphi$ is a phenomenal part of the overall experience $\varepsilon$-as per (i). In virtue of having $\varphi$ as a part, $\varepsilon$ inherits $\varphi$ 's essential properties — as per (ii) — and thereby depends on $\varphi$ for its existence. The other phenomenal states which compose $\varepsilon$ may have an effect on $\varphi$ 's accidental properties (even on those associated with salience). If, for instance, during the jazz concert the volume of all instruments is lowered, except that of the sax, the sound of the sax is likely to become more salient. If it is always the case that some of $\varphi$ 's accidental phenomenal properties depend on the other phenomenal states which compose $\varepsilon$, then condition (iii) is satisfied too. But, of course, $\varepsilon$ is not an introspective state. What $\varepsilon$ lacks and the introspective state has is reference to the target phenomenal state: the introspective state is about the target state, but $\varepsilon$, the overall experience, is not about any of its parts.

Condition (v) ensures that 's reference to $\varphi$ is enabled by the mereological relation specified by (i) and (ii) -it does not occur via an indirect path. When a subject $S$ introspects a phenomenal state $\varphi$, it is in virtue of S's introspectively attending to $\varphi$ that the introspective state $\iota$ refers to $\varphi$. Introspectively attending to $\varphi$, on the integration account, implies that $\varphi$ becomes a part of $\iota$-as per (i) —and that $\iota$ inherits $\varphi$ 's essential properties — as per (ii). Therefore, it is at least partly in virtue of (i) and (ii) that $\iota$ refers to $\varphi$. To understand this more clearly, consider again a phenomenal state $\varphi$ and the overall experience $\varepsilon$ to which it belongs. ${ }^{35}$ Suppose $\varphi$ is a stomachache experience. $\varepsilon$ might include a thought $\theta$ referring to "whatever phenomenal states are co-present with this auditory experience I am currently attending to". In this case, $\varepsilon$ refers to $\varphi$ in virtue of including $\theta$. However, this is not yet a case of introspection: the subject here is attending to their auditory experience, rather than to the stomachache, and reference to the stomachache experience obtains fully independently of the stomachache's phenomenal properties and of $\varepsilon$ 's inheritance of these properties. For the relationship between $\varphi$ and $\iota$ to be introspective, $\iota$ 's reference to $\varphi$ must obtain directly, by the former's being partly constituted by the latter and inheriting its phenomenal properties, rather than via an indirect path like the one just described (i.e. via 's including a mental states that refers to $\varphi$ by a description); hence the

\footnotetext{
properties may be essential to it qua phenomenal state, they are not essential to it qua awareness of stomach distress, or qua part of one's motivation to take an antacid: a state with (slightly) different qualitative phenomenal properties could still be an exemplification of these types. In addition, introspective states may have some essential properties that are not qualitative phenomenal properties, if considered as exemplifications of non-phenomenal types (e.g. functional or epistemic). So, if we consider ı qua functional state or qua epistemic state, its qualitative phenomenal properties are not essential to it. My reply to this objection appeals to the relationship between essence and de re necessity described in $₫ 5.1 .3$. On the view of essential properties I am working with essences entail de re necessity, rather than de dicto necessity. As noted, this implies that objects have properties essentially independently of how they are thought of (and therefore independently of their being considered qua tokens of a certain type). Accordingly, when we attribute some essential properties to an introspective state l, we attribute them to the state itself ( $d e r e$ ), rather than to the state qua an exemplification of a certain type. To be sure, as a consequence of this, if $\iota$ has some essential properties (other than its qualitative phenomenal properties) in virtue of exemplifying types other than phenomenal state (e.g. functional or epistemic state), then those properties should also be attributed de re: they are essential properties of $\iota$. This is consistent with the integration account, which does not rule out is having some essential properties that are not also essential properties of $\varphi$.

34 Thanks to Angela Mendelovici and Geoff Lee for this remark.

${ }^{35}$ For this paragraph's discussion, I am very much indebted to an anonymous referee from EJP.
} 
need for condition (v). ${ }^{36}$ This captures the fact that, in introspection, reference obtains demonstratively, by the subject's attending directly to the phenomenology of the target state, rather than via a description.

My substantial claim about the metaphysics of introspective acquaintance, then, is that, in introspective acquaintance, the relationship between the introspective state and its target is integration: the target phenomenal state is integrated in the introspective state. This means that, when the subject introspects a phenomenal state,

(i) the target state becomes a proper part of the introspective state;

(ii) all of the target state's essential properties are inherited by the introspective state;

(iii) (some of) the target state's accidental phenomenal properties depend on the introspective state;

(iv) the introspective state refers to the target state;

(v) the introspective state refers to the target state partly in virtue of (i) and (ii).

I take (i)-(v) to be necessary and jointly sufficient conditions for introspection of phenomenal states. Condition (i) entails that the introspective state is partly constituted by the target phenomenal state, which makes the integration account a version of the acquaintance view.

As noted, condition (ii) entails that the integrating state cannot exist independently of the integrated state. That is, the introspective state cannot exist independently of the target state. This rules out introspective hallucination: one cannot be in an introspective state in absence of a target phenomenal state. Indeed, it is because it inherits the essential phenomenal properties of the target state that the introspective state cannot exist in its absence. This is a feature of all acquaintance theories, and is preserved in the integration account.

Condition (iii) is that some of the target state's accidental phenomenal properties depend on the introspective state. As noted in $\$ 5.1 .3$, I am assuming here that a phenomenal state's relational and quantitative phenomenal properties are accidental. We saw in $\$ 3$ that, upon being introspected, the target phenomenal state undergoes a change in phenomenal salience and sometimes a change in phenomenal intensity and/or clarity. Such phenomenal changes depend on the introspective state, and at least in the case of salience, they depend on it constitutively. Thus, the integration account explains why phenomenal modification occurs whenever one introspects.

At the same time, as argued in $\$ 5.1 .2$, salience is a relational (or at most quantitative) phenomenal property, while intensity and clarity are quantitative phenomenal properties. Therefore, the phenomenal properties that change when a phenomenal state is introspected are accidental. This means that the phenomenal state continues to exist, albeit altered, once it is introspected. It also means that it was the same state before being phenomenally modified, hence that the introspection did not quite destroy its target. This explains the possibility of introspection.

As noted in $\$ 3$, to meet the phenomenal modification challenge, an account of introspective acquaintance must explain (1) why phenomenal modification associated with salience occurs at every introspective instance and (2) how introspection is possible notwithstanding phenomenal modification. The integration account, I have argued, satisfies both requirements. Condition (iii) explains both (1) and (2). It explains what grounds the fact that change in salience occurs whenever one

\footnotetext{
36 Other acquaintance theorists, moved by similar considerations, adopt a similar solution. See e.g. Gertler (2001: 307): “ $S$ introspects her occurrent phenomenal state token $a$, with phenomenal content $F$, iff $S$ has an occurrent mental token $b$ which is such that: (i) $a$ is embedded in $b$; (ii) $b$ refers to $F$; and (iii) (ii) is true partly in virtue of (i)."
} 
introspects. Whenever it is integrated, some of the target phenomenal state's phenomenal properties (notably its specific salience) depend on the presence of the introspective state. When not introspected, the target state is less salient. Therefore, when it is introspected, the target state undergoes a phenomenal change. Indeed, the post-change phenomenal state depends on the introspective state. The phenomenal properties associated with salience, those that change whenever the target state is introspected, are those which constitutively depend on the introspective state. Therefore, the target phenomenal state, as modified by the introspective activity, depends on the introspective state.

However, the integration account is compatible with the target state's having independent existence from the introspective state. Since the target phenomenal state $\varphi$ has the same essential properties before and while being introspected, and phenomenal states are individuated by their essential properties, post-change $\varphi$ is the same token state as pre-change $\varphi$, though it differs in (some of) its accidental properties. The integration account is thus consistent with the independence intuition. This allows us to see how the integration account satisfies (2). Even though the target phenomenal state undergoes some phenomenal changes upon being introspected, such changes do not concern its essence, what makes it the state it is: they only concern its accidental phenomenal properties. Therefore, what is integrated into the introspective state is exactly the same phenomenal state which preexisted and was targeted by the introspective act. Phenomenal-state introspection is possible despite phenomenal modification because only the accidental phenomenal properties are modified by the introspective act - the essential properties, which individuate the target phenomenal state remain, unchanged.

In conclusion, the integration account joins other acquaintance accounts in denying introspective state's ontological independence from their target states, thus ruling out introspective hallucination. But in addition it explains the phenomenon of phenomenal modification while doing justice to the intuition that phenomenal states can exist un-introspected and making sense of the possibility of introspection. For these reasons, I take it to be a good account of introspective acquaintance. The integration account relies on some assumptions about the metaphysics of the mind, which I have attempted to spell out but not to defend. As noted, based on different assumptions, alternative accounts of the metaphysics of introspective acquaintance could be explored. In the absence of such competitors, though, we may consider the integration account the best version of the acquaintance view of phenomenal-state introspection. ${ }^{37}$

\footnotetext{
37 This work was supported by the French National Research Agency's grants ANR-17-EURE-0017 FrontCog and ANR-10-IDEX-0001-02 PSL. For many conversations on this paper's topic and for through comments on previous drafts I am infinitely grateful to Uriah Kriegel. The paper was presented in the Syracuse University Philosophy Graduate Conference 2018, in the University of Toronto Graduate Conference 2018, in the Congrès International triennal 2018 de la SoPhA in Louvain-la Neuve, in the Acquaintance and Direct Grasp conference in Paris, in the Tenth international conference of the German Society for Analytic Philosophy in Cologne, in the closing Conference of the FWF Project Franz Brentano's Descriptive Psychology in Salzburg, and in the Phenomenal Consciousness and Self-Awareness workshop in Fribourg. I am grateful to the audiences there, in particular to Stacy Kohls, Yaojun Lu, Trenton Merricks, Adam Patterson, Kara Richardson, Jan Swiderski, Louis Gularte, Aaron Henry, Cheryl Misak, Daniel Munro, Melissa Rees, Julia Smith, David Bourget, Géraldine Carranante, David Chalmers, Eli Chudnoff, François Kammerer, Andrew Lee, Geoff Lee, Farid Masrour, Olivier Massin, Angela Mendelovici, Takuya Niikawa, Susanna Schellenberg, Charles Siewert, Alfredo Tomasetta, Jérôme Dokic, Deborah
} 


\section{References}

Armstrong, David M. 1968. A Materialist Theory of the Mind. New York: Humanities Press.

Balog, Katalin. 2012. “Acquaintance and the Mind-Body Problem.” In New Perspectives on Type Identity: The Mental and the Physical, edited by Simone Gozzano and Christopher S. Hill, 16-42. Cambridge: Cambridge University Press.

Bayne, Tim. 2010. The Unity of Consciousness. Oxford: Oxford University Press.

Bigelow, John, and Robert Pargetter. 1990. "Acquaintance with Qualia." Theoria 56 (3): 129-47.

- 2006. "Re-Acquaintance with Qualia." Australasian Journal of Philosophy 84 (3): 353-78.

BonJour, Laurence. 2000. "Toward a Defense of Empirical Foundationalism." In Resurrecting OldFashioned Foundationalism, edited by Michael R. DePaul. Lanham, Ma: Rowman and Littlefield. - 2003. "A Version of Internalist Foundationalism." In Epistemic Justification: Internalism vs. Externalism, Foundations vs. Virtues, by Laurence Bonjour and Ernest Sosa. Malden, MA: Blackwell.

Brewer, Bill. 2011. Perception and Its Objects. Oxford: Oxford University Press.

Byrne, Alex. 2005. "Introspection." Philosophical Topics 33 (1): 79-104.

Campbell, John. 2002. Reference and Consciousness. Oxford: Clarendon Press.

- 2019. “Acquaintance as Grounded in Joint Attention.” In Acquaintance: New Essays, edited by Jonathan Knowles and Thomas Raleigh, 215-26. Oxford: Oxford University Press.

Carruthers, Peter. 2005. Consciousness: Essays from a Higher-Order Perspective. Oxford: Oxford University Press.

Cassam, Quassim. 2015. Self-Knowledge for Humans. Oxford, New York: Oxford University Press.

Chalmers, David J. 2003. "The Content and Epistemology of Phenomenal Belief." In Consciousness: New Philosophical Perspectives, edited by Quentin Smith and Aleksandar Jokic, 220-72. Oxford; New York: Oxford University Press.

Comte, Auguste. 1830. Cours de philosophie positive. Edited by Florence Khodoss and Pierre Hidalgo. Vol. 3. Grenoble: La Gaya Scienza.

Conee, Earl. 1994. "Phenomenal Knowledge." Australasian Journal of Philosophy 72 (2).

Dennett, Daniel C. 1988. "Quining Qualia.” In Consciousness in Contemporary Science, edited by Anthony J. Marcel and Edoardo Bisiach. Oxford: Oxford University Press.

Fales, Evan. 1996. A Defense of the Given. Lanham, Ma: Rowman \& Littlefield Publishers.

Fine, Kit. 1994. "Essence and Modality: The Second Philosophical Perspectives Lecture." Philosophical Perspectives 8: 1-16.

Frankish, Keith. 2016. "Illusionism as a Theory of Consciousness." Journal of Consciousness Studies 23 (11-12): 11-39.

Fumerton, Richard. 1996. Metaepistemology and Skepticism. 1 vols. Studies in Epistemology and Cognitive Theory. Lanham, Ma: Rowman \& Littlefield.

. 2001. "Classical Foundationalism." In Resurrecting Old-Fashioned Foundationalism, edited by Michael R. DePaul, 3-20. Studies in Epistemology and Cognitive Theory. Lanham, Ma: Rowman and Littlefield.

. 2009. "Luminous Enough for a Cognitive Home." Philosophical Studies 142 (1): 67-76.

Gertler, Brie. 2001. "Introspecting Phenomenal States." Philosophy and Phenomenological Research 63 (2): 305-28.

- 2011. Self-Knowledge. London; New York: Routledge.

Marber, Michael Murez, Christine Tappolet, Sacha Fink, Luke Roelofs, Tobias Schlicht, Johannes Brandl, Tim Crane, Arnaud Dewalque, Guillaume Fréchette, Denis Seron, Hamid Taieb, Julien Bugnon, Daniel Morgan, Michelle Liu, and Carlota Serrahima. 
- 2012. "Renewed Acquaintance." In Introspection and Consciousness, edited by Declan Smithies and Daniel Stoljar, 89-123. Oxford: Oxford University Press.

Grzankovski, Alex, and Michael Tye. 2019. "What Acquaintance Teaches." In Acquaintance: New Essays, edited by Jonathan Knowles and Thomas Raleigh, 75-94. Oxford: Oxford University Press.

Hasan, Ali. 2013. "Phenomenal Conservatism, Classical Foundationalism, and Internalist Justification." Philosophical Studies: An International Journal for Philosophy in the Analytic Tradition 162 (2): 119-41.

Hellie, Benj. 2010. "An Externalist's Guide to Inner Experience.” In Perceiving the World, edited by Bence Nanay, 97-145. Oxford: Oxford University Press.

Horgan, Terence, and Uriah Kriegel. 2007. "Phenomenal Epistemology: What Is Consciousness That We May Know It so Well?” Philosophical Issues 17 (1): 123-144.

Jackson, Frank. 1982. “Epiphenomenal Qualia.” The Philosophical Quarterly 32 (127): 127-36.

James, William. 1890. The Principles of Psychology. London: Dover, 1950.

Kammerer, François. 2016. "The Hardest Aspect of the Illusion Problem--and How to Solve It." Journal of Consciousness Studies 23 (11-12): 124-39.

Kant, Immanuel. 1786. "Metaphysical Foundations of Natural Science." In Kant's Prolegomena, and Metaphysical Foundations of Natural Science, by Immanuel Kant, translated by Ernest Belfort Bax. London: G. Bell.

Kim, Jaegwon. 1993. Supervenience and Mind: Selected Philosophical Essays. Cambridge Studies in Philosophy. Cambridge: Cambridge University Press.

Knowles, Jonathan, and Thomas Raleigh. 2019. Acquaintance: New Essays. Oxford: Oxford University Press.

Kriegel, Uriah. 2009. Subjective Consciousness: A Self-Representational Theory. Oxford: Oxford University Press.

—. 2012. "Personal-Level Representation.” Protosociology 28: 77-114.

Levine, Joseph. 2019. "Acquaintance is Consciousness and Consciousness is Acquaintance." In Acquaintance: New Essays, edited by Jonathan Knowles and Thomas Raleigh, 33-48. Oxford: Oxford University Press.

Lycan, William G. 1996. Consciousness and Experience. Cambridge, MA: MIT Press.

Mill, John Stuart. 1882. Auguste Comte and Positivism. London: Trübner.

Mole, Christopher. 2008. “Attention and Consciousness.” Journal of Consciousness Studies 15 (4): 86-104.

Moran, Richard. 2001. Authority and Estrangement: An Essay on Self- Knowledge. Princeton, NJ: Princeton University Press.

Nanay, Bence, ed. 2010. Perceiving the World. Oxford: Oxford University Press.

Pitt, David. 2004. “The Phenomenology of Cognition Or What Is It Like to Think That P?” Philosophy and Phenomenological Research 69 (1): 1-36.

Prinz, Jesse. 2011. "Is Attention Necessary and Sufficient for Consciousness?” In Attention: Philosophical and Psychological Essays, edited by Christopher Mole, Declan Smithies, and Wayne Wu, 174203. Oxford; New York: Oxford University Press.

Raleigh, Thomas. 2019. "The Recent Renaissance of Acquaintance.” In Acquaintance: New Essays, edited by Jonathan Knowles and Thomas Raleigh, 1-31. Oxford: Oxford University Press.

Recanati, François. 2010. "Singular Thought: In Defence of Acquaintance." In New Essays on Singular Thought, edited by Robin Jeshion, 141-90. Oxford: Oxford University Press. https://wwwoxfordscholarship-

com.ezproxy.rice.edu/view/10.1093/acprof:oso/9780199567881.001.0001/acprof9780199567881-chapter-6.

Rosenthal, David M. 2005. Consciousness and Mind. Oxford: Clarendon Press.

Russell, Bertrand. 1912. The Problems of Philosophy. New York: H. Holt and Company. 
Ryle, Gilbert. 1949. The Concept of Mind. Chicago: The University of Chicago Press.

Siewert, Charles. 1998. The Significance of Consciousness. Princeton: Princeton University Press.

Smithies, Declan. 2011. "Attention Is Rational-Access Consciousness." In Attention: Philosophical and Psychological Essays, edited by Christopher Mole, Declan Smithies, and Wayne Wu, 247-73. Oxford; New York: Oxford University Press.

Soteriou, Matthew. 2013. The Mind's Construction: The Ontology of Mind and Mental Action. Oxford, New York: Oxford University Press.

Stazicker, James. 2011. "Attention, Visual Consciousness and Indeterminacy." Mind and Language 26 (2): $156-84$.

Titchener, Edward B. 1912a. "Prolegomena to a Study of Introspection." The American Journal of Psychology 23 (3): 427-48.

. 1912b. "The Schema of Introspection." The American Journal of Psychology 23 (4): 485-508.

Watzl, Sebastian. 2017. Structuring Mind. The Nature of Attention and How It Shapes Consciousness. Oxford: Oxford University Press.

Williford, Kenneth. 2015. "Representationalisms, Subjective Character, and Self-Acquaintance." In Open MIND, edited by Thomas Metzinger and Jennifer M. Windt. Vol. 39. Frankfurt am Main: MIND Group.

Wundt, Wilhelm Max. 1897. Outlines of Psychology. Leipzig; New York: Engelmann. http://archive.org/details/cu31924014474534. 